\title{
Integrated analysis of genes associated with poor prognosis of patients with colorectal cancer liver metastasis
}

\author{
Zhenyuan Qian', Guobing Zhang ${ }^{2}$, Guangyuan Song ${ }^{3}$, Ji Shi' ${ }^{3}$, Lijie Gong ${ }^{3}$, Yiping \\ Mou $^{1,4}$, Yong Han ${ }^{5}$ \\ ${ }^{1}$ Department of Gastrointestinal Surgery, Zhejiang Provincial People's Hospital, Hangzhou, Zhejiang 310014, P.R. China \\ ${ }^{2}$ Department of Pharmacy, Zhejiang Provincial People's Hospital, Hangzhou, Zhejiang 310014, P.R. China \\ ${ }^{3}$ Zhejiang Chinese Medical University, Hangzhou, Zhejiang 310053, P.R. China \\ ${ }^{4}$ Key Laboratory of Gastroenterology of Zhejiang Province, Zhejiang Provincial People's Hospital, Hangzhou, Zhejiang \\ 310014, P.R. China \\ ${ }^{5}$ Clinical Research Institute, Zhejiang Provincial People's Hospital, Hangzhou, Zhejiang 310014, P.R. China \\ Correspondence to: Guobing Zhang, email: 13675851802@163.com
}

Keywords: colorectal cancer, prognostic marker, liver metastasis

Received: November 30, $2016 \quad$ Accepted: February 07, $2017 \quad$ Published: March 10, 2017

Copyright: Qian et al. This is an open-access article distributed under the terms of the Creative Commons Attribution License (CC-BY), which permits unrestricted use, distribution, and reproduction in any medium, provided the original author and source are credited

\section{ABSTRACT}

Colorectal cancer (CRC) is one of the most common malignances in the gut. Liver is the most common metastasis site of CRC. This study focuses on the primary CRC and its liver metastasis, aiming to discover several liver metastasis related genes and provide therapeutic candidates. We compared gene expression patterns among the groups of normal colorectal mucosa, primary tumor and the liver metastasis using a CRC gene expression dataset. 84 genes were found to be upregulated in both primary tumor and liver metastases. Function enrichment analysis indicated that these genes are enriched in pathways such as chemotaxis, coagulation and lipid metabolism which are crucial in multi-step cancer metastasis. Gene network analysis identified several important hub genes that may be involved in carcinogenesis and liver metastasis. Then we used a validation dataset containing 562 CRC samples with detailed clinical information, to screen prognostic biomarkers for overall survival (OS) and relapse free survival (RFS). Finally, overexpression of THBS2 (thrombospondin 2), INHBB (inhibin, beta B) and BGN (biglycan) were proved to be correlated with poor OS and RFS. In conclusion, this study indicated that chemotaxis, coagulation and lipid metabolism might play critical roles in the processes of carcinogenesis and liver metastasis. THBS2, INHBB and BGN are prognostic markers and potential therapeutic targets for CRC.

\section{INTRODUCTION}

Colorectal cancer (CRC) is one of the most common malignances in the digest system [1-3]. Frequently, distal metastasis affects clinical outcomes. Colorectal cancer liver metastasis (CRCLM) is the most common metastasis pattern in CRC [4]. It is possible to have a radical surgery on advanced colorectal cancer accompanied with liver metastasis in certain cases $[4,5]$. It is also probable to cure thoroughly by radical surgery, radio-chemotherapy, and molecular targeted therapy [6-9]. Unfortunately, such patients only accounts for a very small proportion while most CRCLM patients have poor outcomes.
Therefore, two questions need to be addressed. Firstly, which subgroup of CRC patients will progress to liver metastasis? Secondly, which subgroup of patients with CRCLM will have poorer prognosis? Investigations on novel prognostic biomarkers and therapeutic targets are needed to improve the outcomes of CRCLM patients.

\section{RESULTS}

Flow chart of this study

This study focuses on the carcinogenesis and liver metastasis of CRC (Figure 1). Firstly, we searched Gene 
Expression Omnibus (GEO) for choosing appropriate dataset for further analysis (GSE68468). Then we compared the gene expression pattern between normal colon mucosa and primary tumors; primary tumor and liver metastasis, respectively. Genes upregulated in both primary tumors and liver metastasis were selected for function enrichment analysis, gene-gene interaction analysis and prognostic power evaluation.

\section{Identification of upregulated genes in both primary tumor and liver metastasis}

The genes expression patterns of 54 normal colon mucosa (N), 186 primary tumors (PT) and 54 liver metastases (LM) were compared to discover upregulated genes in both PT and LM. 100 probes representing 84 genes were found to be upregulated in both PT and LM (Figure 2 and Table 1). Heat map visualization of 84 upregulated genes in N, PT and LM samples was demonstrated in Figure 3. Function enrichment of these 84 upregulated genes indicated that chemotaxis, coagulation and lipid metabolism etc. were critical signaling pathways (Figure 4). Gene-gene interaction network was constructed (Figure 5) and hub genes were listed in Table 2 (degree $\geq 15)$.

\section{Evaluation the prognostic power of 84 upregulated genes}

A dataset containing 562 samples was utilized to evaluate the prognostic power of 84 upregulated genes. The expression of each gene was defined as high expression and low expression by quartile division at the cutoff of $25 \%, 50 \%$ and $75 \%$. Then we analyzed the relationship between survival and gene expression at different cutoff level. Survival analysis results indicated that four hub genes, namely thrombospondin 2 (THBS2), inhibin beta $\mathrm{B}$ (INHBB), biglycan (BGN), and serpin peptidase inhibitor, clade $\mathrm{E}$ (nexin, plasminogen activator inhibitor type 1), member 1 (SERPIN1) were associated with both OS and RFS (Figure 6, cut-off value: upper quartiles of gene expression, $\mathrm{p}<0.05)$. Since the association between

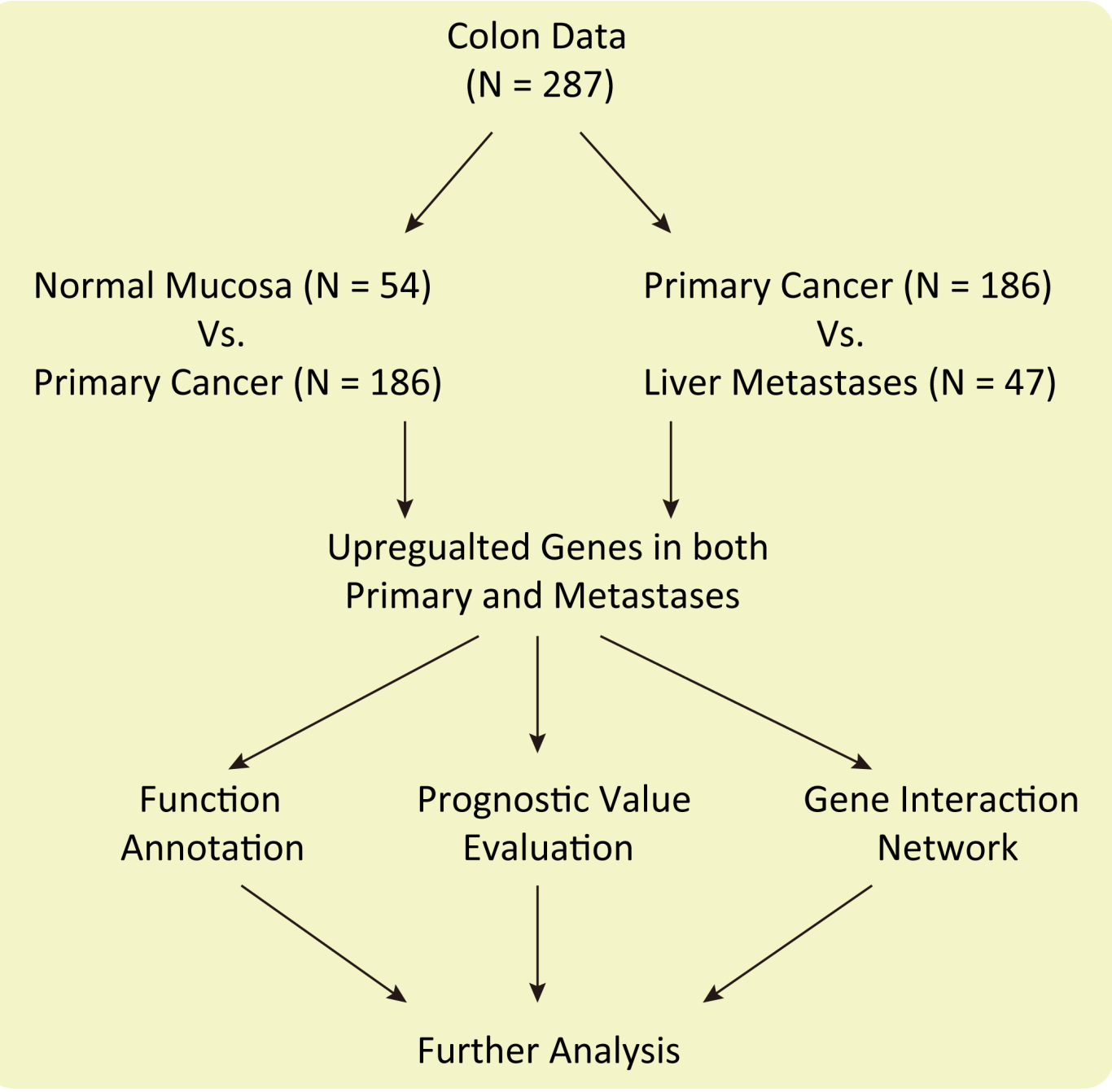

Figure 1: Flow chart of this study. 
SERPIN1 and CRC metastasis has been reported [10, 11], we chose THBS2, INHBB and BGN for further study.

\section{The prognostic power of three hub genes in different tumor stages}

Patients were divided into groups of stage 0-II and stage III-IV. Then the prognostic power of each hub genes were tested on these two groups separately. Figure 7 indicated that prognostic power of THBS2 and INHBB were independent from tumor staging (cut-off value: upper quartiles, $\mathrm{P}<0.05$ ). However, $\mathrm{BGN}$ was not an independent prognostic marker (cut-off value: upper quartiles, $\mathrm{P}>0.05$ ).

\section{Combination of three hub genes for predicting OS and RFS}

According to the expression level of three hub genes (cut-off value: upper quartiles), samples are divided into four groups: triple high expression, double high expression, double low expression and triple low expression, respectively (TH, DH, DL and TL). TL patients have the best survival for OS and RFS while the survival of $\mathrm{TH}$ patients are the worst $(\mathrm{p}<0.5)$. There was no significant difference between DL and DH groups (Figure 8).

\section{DISCUSSION}

Colorectal cancer with liver metastasis (CRCLM) is the research hotspot in recent years [12]. As is known, liver is the most common metastasis site of colorectal cancer, because of dissemination via the portal venous system. About 10\% CRCLM can be resected by surgery, however, only $25 \%-50 \%$ of them could be free of recurrence after treatments [13]. Cheng D et al. reported that MicroRNA $-20 \mathrm{a}-5 \mathrm{p}$, as an intermediator, may promote the ability of invasion and metastasis in colorectal cancer by suppressing

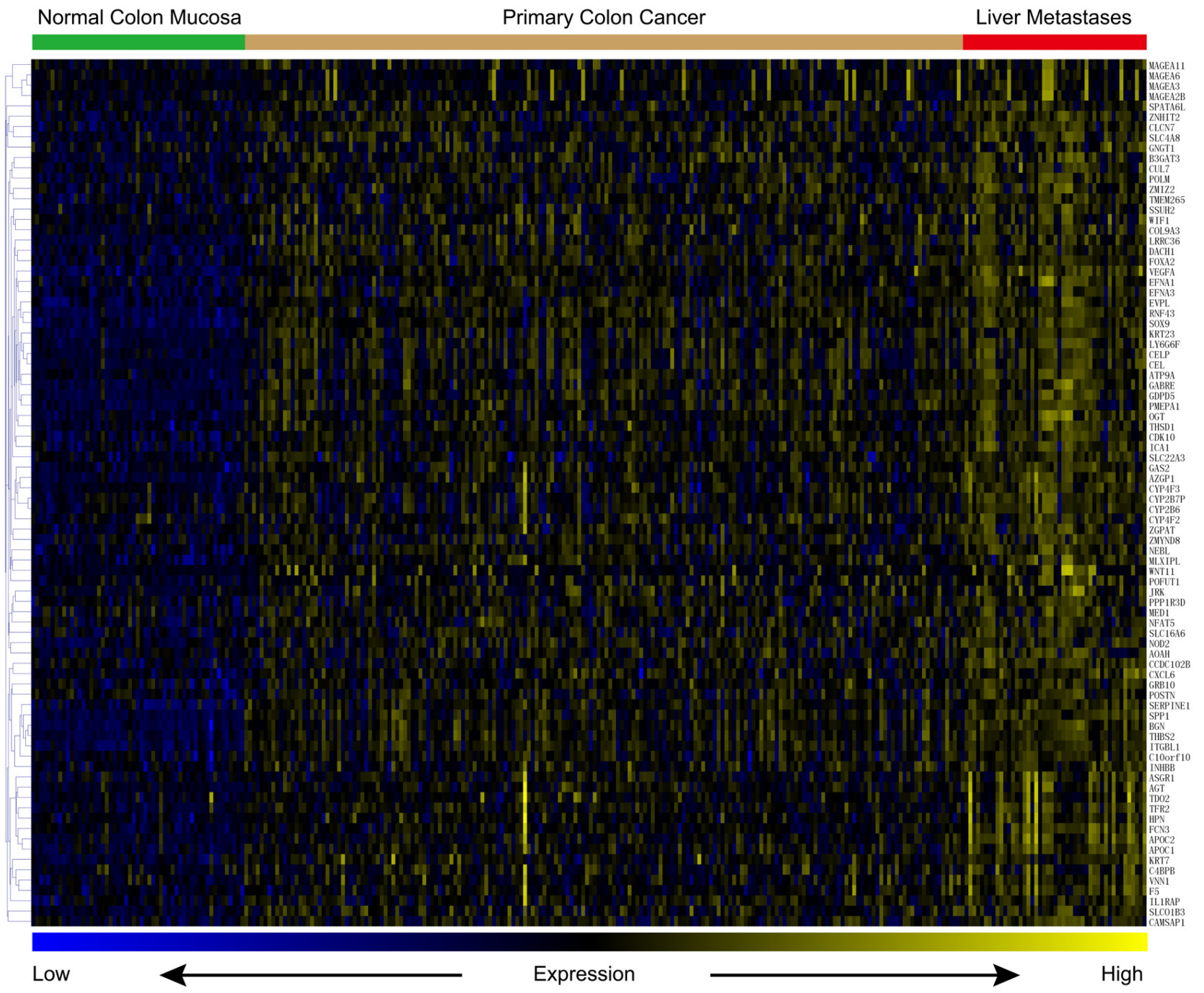

Figure 2: Heat map of 84 upregulated genes in both PT and LM. 
Table 1: 84 genes upregulated in both primary tumor and liver metastasis

\begin{tabular}{|c|c|}
\hline Gene Symbol & Gene Title \\
\hline EFNA1 & ephrin A1 \\
\hline SERPINE1 & serpin family E member 1 \\
\hline AGT & angiotensinogen \\
\hline SOX9 & SRY-box 9 \\
\hline THBS2 & thrombospondin 2 \\
\hline B3GAT3 & beta-1,3-glucuronyltransferase 3 \\
\hline CDK10 & cyclin dependent kinase 10 \\
\hline MED1 & mediator complex subunit 1 \\
\hline CUL7 & cullin 7 \\
\hline APOC1 & apolipoprotein $\mathrm{C} 1$ \\
\hline EVPL & envoplakin \\
\hline GABRE & gamma-aminobutyric acid type A receptor epsilon subunit \\
\hline PPP1R3D & protein phosphatase 1 regulatory subunit 3D \\
\hline APOC2 & apolipoprotein $\mathrm{C} 2$ \\
\hline WIF1 & WNT inhibitory factor 1 \\
\hline F5 & coagulation factor $\mathrm{V}$ \\
\hline COL9A3 & collagen type IX alpha 3 chain \\
\hline $\mathrm{HPN}$ & hepsin \\
\hline INHBB & inhibin beta B subunit \\
\hline SLC22A3 & solute carrier family 22 member 3 \\
\hline ITGBL1 & integrin subunit beta like 1 \\
\hline DACH1 & dachshund family transcription factor 1 \\
\hline $\mathrm{AOAH}$ & acyloxyacyl hydrolase \\
\hline VNN1 & vanin 1 \\
\hline GAS2 & growth arrest specific 2 \\
\hline FCN3 & ficolin 3 \\
\hline CEL & carboxyl ester lipase \\
\hline TDO2 & tryptophan 2,3-dioxygenase \\
\hline CXCL6 & C-X-C motif chemokine ligand 6 \\
\hline SLCO1B3 & solute carrier organic anion transporter family member 1B3 \\
\hline CYP4F2 & cytochrome P450 family 4 subfamily F member 2 \\
\hline CYP4F3 & cytochrome P450 family 4 subfamily F member 3 \\
\hline WNT11 & Wnt family member 11 \\
\hline SSUH2 & ssu-2 homolog (C. elegans) \\
\hline ASGR1 & asialoglycoprotein receptor 1 \\
\hline CYP2B7P & cytochrome P450 family 2 subfamily B member 7 , pseudogene \\
\hline CYP2B6 & cytochrome P450 family 2 subfamily B member 6 \\
\hline SLC16A6 & solute carrier family 16 member 6 \\
\hline SLC4A8 & solute carrier family 4 member 8 \\
\hline ZMYND8 & zinc finger MYND-type containing 8 \\
\hline GNGT1 & G protein subunit gamma transducin 1 \\
\hline CELP & carboxyl ester lipase pseudogene \\
\hline
\end{tabular}

(Continued) 


\begin{tabular}{|c|c|}
\hline Gene Symbol & Gene Title \\
\hline LY6G6F & lymphocyte antigen 6 complex, locus G6F \\
\hline C4BPB & complement component 4 binding protein beta \\
\hline KRT7 & keratin 7 \\
\hline C10orf10 & chromosome 10 open reading frame 10 \\
\hline CLCN7 & chloride voltage-gated channel 7 \\
\hline AZGP1 & alpha-2-glycoprotein 1, zinc-binding \\
\hline SPP1 & secreted phosphoprotein 1 \\
\hline MAGEA3 & MAGE family member A3 \\
\hline FOXA2 & forkhead box A2 \\
\hline EFNA3 & ephrin A3 \\
\hline TFR2 & transferrin receptor 2 \\
\hline IL1RAP & interleukin 1 receptor accessory protein \\
\hline POFUT1 & protein O-fucosyltransferase 1 \\
\hline MAGEA11 & MAGE family member A11 \\
\hline VEGFA & vascular endothelial growth factor A \\
\hline OGT & O-linked N-acetylglucosamine (GlcNAc) transferase \\
\hline GDPD5 & glycerophosphodiester phosphodiesterase domain containing 5 \\
\hline TMEM265 & transmembrane protein 265 \\
\hline BGN & biglycan \\
\hline ICA1 & islet cell autoantigen 1 \\
\hline MAGEA2B & MAGE family member A2B \\
\hline MAGEA6 & MAGE family member A6 \\
\hline JRK & Jrk helix-turn-helix protein \\
\hline POSTN & periostin \\
\hline NFAT5 & nuclear factor of activated T-cells 5 \\
\hline GRB10 & growth factor receptor bound protein 10 \\
\hline АТР9А & ATPase phospholipid transporting 9A (putative) \\
\hline NEBL & nebulette \\
\hline PMEPA1 & prostate transmembrane protein, androgen induced 1 \\
\hline RNF43 & ring finger protein 43 \\
\hline KRT23 & keratin 23 \\
\hline ZNHIT2 & zinc finger HIT-type containing 2 \\
\hline THSD1 & thrombospondin type 1 domain containing 1 \\
\hline LRRC36 & leucine rich repeat containing 36 \\
\hline NOD2 & nucleotide binding oligomerization domain containing 2 \\
\hline SPATA6L & spermatogenesis associated 6 like \\
\hline CCDC102B & coiled-coil domain containing 102B \\
\hline CAMSAP1 & calmodulin regulated spectrin associated protein 1 \\
\hline MLXIPL & MLX interacting protein like \\
\hline ZMIZ2 & zinc finger MIZ-type containing 2 \\
\hline ZGPAT & zinc finger $\mathrm{CCCH}$-type and G-patch domain containing \\
\hline POLM & DNA polymerase mu \\
\hline
\end{tabular}


Smad4 [14]. Mismatch repair deficiency status, such as frequent PIK3CA mutation, was also seemed as a cause to carcinogenesis in colorectal cancer $[15,16]$. Moreover, microsatellite instability in colorectal cancer was also very important. For example, methylation of ITF2 plays a role in modulating WNT signaling in CRC [17]. However, key gene regulators related to carcinogenesis and metastasis of CRC are still unclear. Therefore, discovering novel genes associated with CRCLM and distinguishing new prognostic biomarkers are critical for managing patients with CRCLM.
In this study, 84 genes were found to be associated with the carcinogenesis and liver metastasis of CRC. Chemotaxis, coagulation and lipid metabolism are key signaling pathways involved in carcinogenesis and liver metastasis. By performed gene-gene interaction network analysis, 32 hub genes were discovered. Kaplan-Meier analysis was performed for each gene separately, and SERPINE1, THBS2, INHBB and BGN were found to be associated with poorer OS and RFS.

Metastasis to distant organs is a multistage process: local invasion, intravasation, survival in the circulation, extravasation and colonization [18]. The

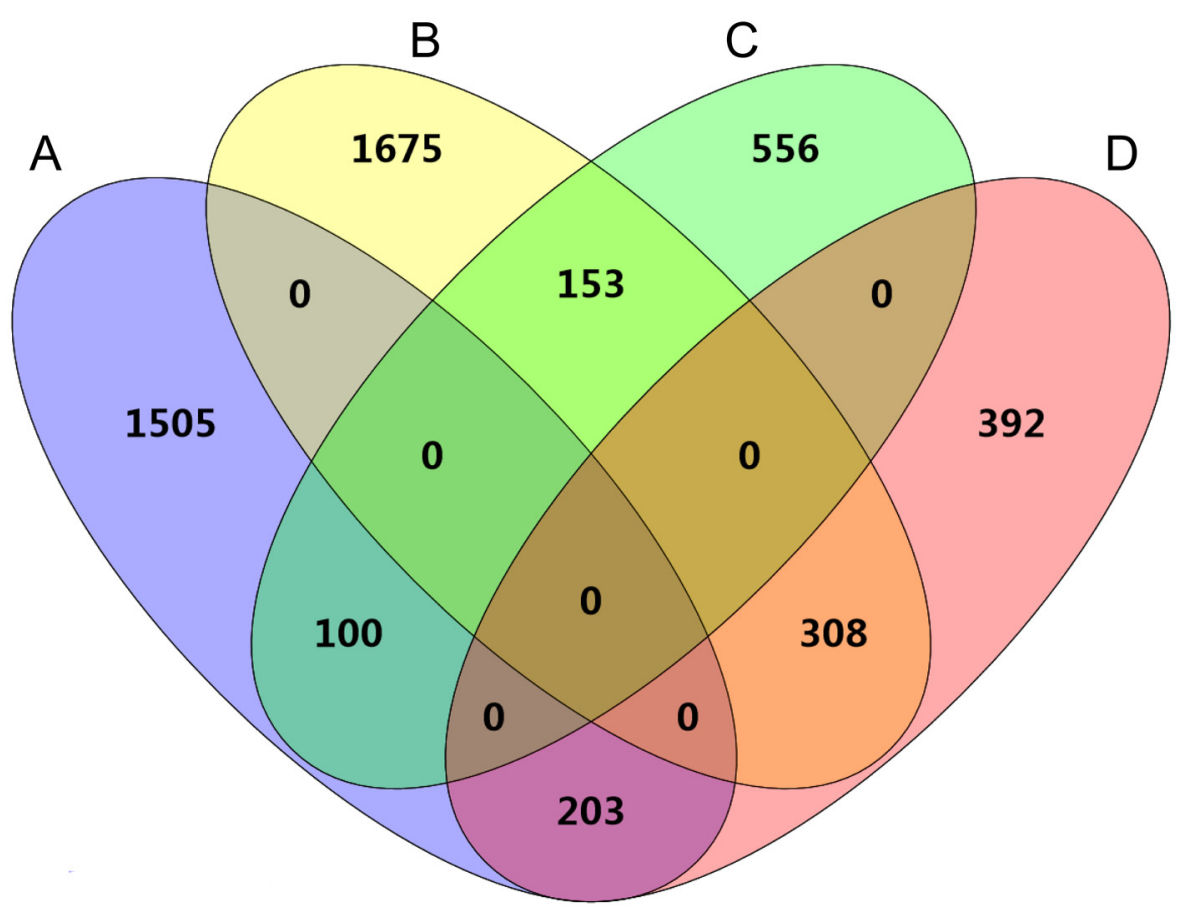

Figure 3: Venn diagram of differentially expressed genes in PT vs. N and PT vs. LM. (A) genes upregulated in PT compared to N. (B) genes down regulated in PT compared to N. (C) genes upregulated in LM compared to PT. (D) genes down regulated in LM compared to PT.

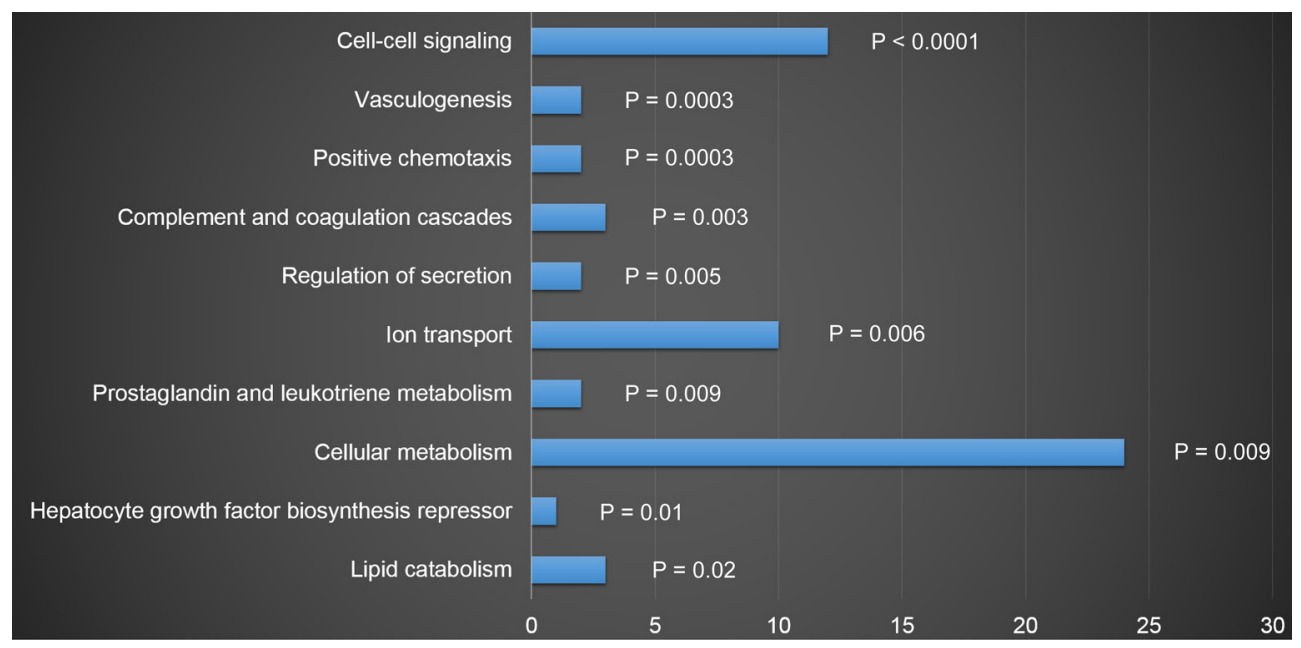

Figure 4: Function enrichment of 84 genes upregulated in both PT and LM. 
activation of the coagulation system and platelets have a critical role in the progression of cancer [19]. By forming cell aggregates that protect tumour cells from immune surveillance or by collaborating during extravasation, tumour cell-platelet interactions could also enable dissemination [20-23]. Chemotaxis and vasculogenesis in cancer are crucial for increasing vascular permeability which could improve extravasation and lead to metastasis eventually [19]. In the present study, we showed that chemotaxis and coagulation processes etc. are key characteristics CRC progression and are potential therapeutic targets.

SERPINE1 encodes a member of the serine proteinase inhibitor superfamily which is the principal inhibitor of tissue plasminogen activator (tPA) and urokinase (uPA), and hence is a inhibitor of fibrinolysis. It reacts directly to integrin, uPA-uPAR and ECM, causing to invade and migrate to surrounding and distance [10, 24]. Meanwhile, SERPINE1 has been considered as biomarker related to poorer prognosis in CRC [11]. Since there are few reports on THBS2, INHBB and BGN in $\mathrm{CRC}$, especially in CRCLM, we chose these three genes for further analysis.
THBS2, a member of thrombospondin family, is a disulfide-linked homotrimeric glycoprotein that mediates cell-to-cell and cell-to-matrix interactions, and hence modulates the cell adhesion and migration. Initially, THBS2 was thought to be related to heart failure [25]. Subsequently, it's also found linked to poorer prognosis in oral cavity squamous cell carcinoma [26]. Interestingly, in many other carcinomas, THBS2 was found downregulated and was correlated with poorer prognosis in tumors such as gastric cancer [27, 28], prostate cancer [29] and breast cancer [30]. In the present study, we found that THBS2 was overexpressed in both primary colon tumor and liver metastases. Moreover, its expression was negatively correlated with OS and RFS.

INHBB is the subunit of inhibin, which regulates gonadal stromal cell proliferation negatively and has tumorsuppressor activity. It seems as an independent prognostic parameter in uterine non-endometrioid cancer, and a low expression demonstrates a significant better cause-specific survival [31]. Investigating the effects of INHBB gene knockdown on the development of mouse granulosa cells in vitro, Mohamed et al. found INHBB has the function of inhibiting apoptosis in mouse granulosa cell [32]. However,

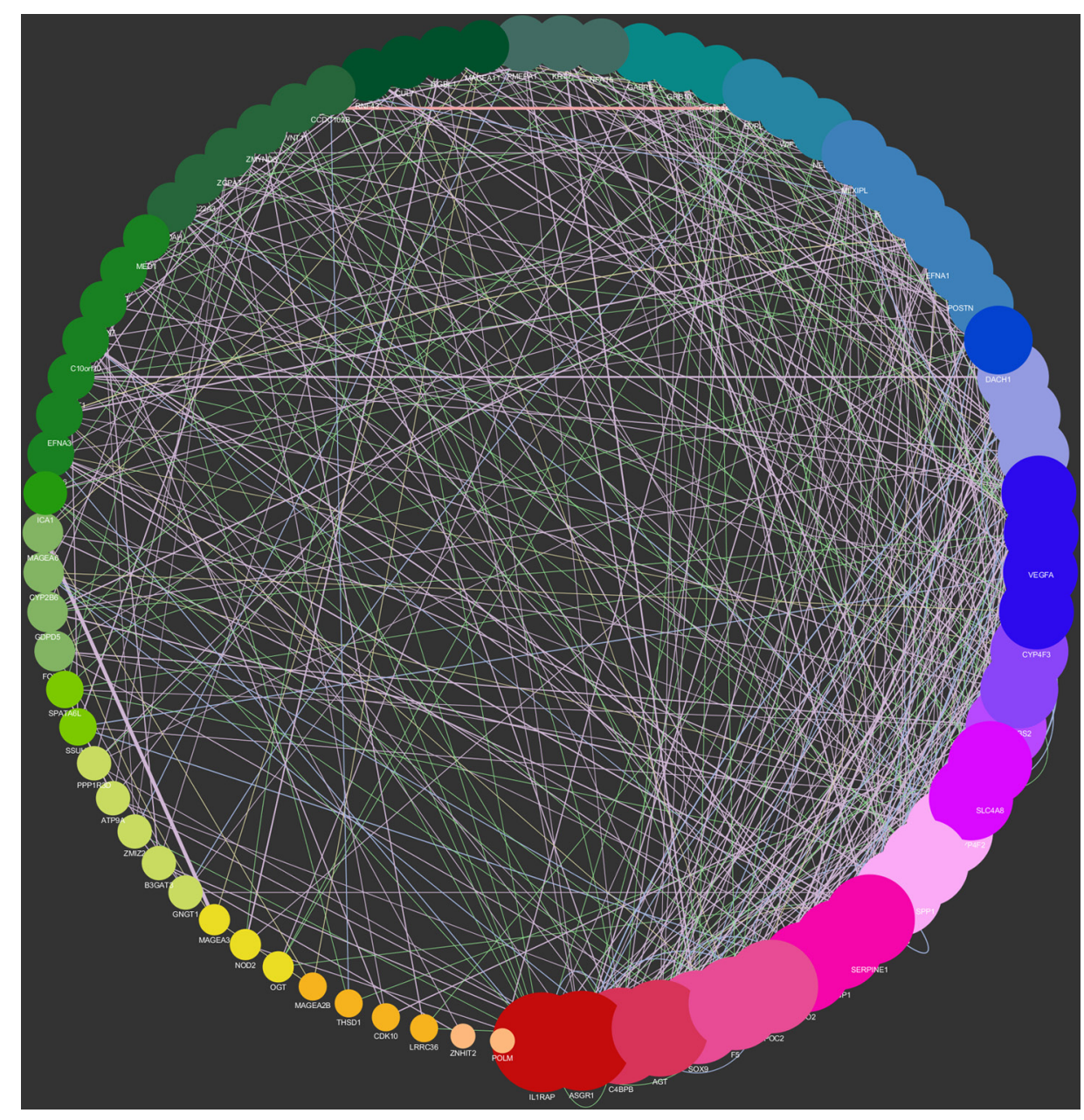

Figure 5: Gene-gene interaction network of 84 genes upregulated in both PT and LM. 
Table 2: Network analysis of 84 upregulated genes in both PT and LM (Degree $\geq 15)$

\begin{tabular}{|c|c|c|c|}
\hline Gene Symbol & Degree & $\begin{array}{c}\text { Average Shortest Path } \\
\text { Length }\end{array}$ & Clustering Coefficient \\
\hline ASGR1 & 28 & 1.74358974 & 0.29347826 \\
\hline IL1RAP & 28 & 1.80769231 & 0.22529644 \\
\hline AGT & 27 & 1.79487179 & 0.36758893 \\
\hline C4BPB & 27 & 1.75641026 & 0.24675325 \\
\hline SOX9 & 25 & 1.80769231 & 0.21212121 \\
\hline APOC2 & 25 & 1.83333333 & 0.4 \\
\hline F5 & 25 & 1.82051282 & 0.34632035 \\
\hline TDO2 & 23 & 1.87179487 & 0.33986928 \\
\hline AZGP1 & 23 & 1.82051282 & 0.28063241 \\
\hline SERPINE1 & 23 & 1.80769231 & 0.27619048 \\
\hline INHBB & 22 & 1.84615385 & 0.19883041 \\
\hline SPP1 & 22 & 1.88461538 & 0.24836601 \\
\hline CXCL6 & 22 & 1.87179487 & 0.27368421 \\
\hline SLC4A8 & 21 & 1.82051282 & 0.22222222 \\
\hline CYP4F2 & 21 & 1.91025641 & 0.19852941 \\
\hline HPN & 20 & 1.82051282 & 0.31052632 \\
\hline SLCO1B3 & 19 & 1.88461538 & 0.35833333 \\
\hline THBS2 & 19 & 1.8974359 & 0.25735294 \\
\hline VEGFA & 18 & 1.8974359 & 0.19852941 \\
\hline CYP4F3 & 18 & 1.97435897 & 0.32967033 \\
\hline APOC1 & 18 & 1.93589744 & 0.34065934 \\
\hline GAS2 & 18 & 1.92307692 & 0.2952381 \\
\hline TFR2 & 17 & 1.98717949 & 0.59090909 \\
\hline VNN1 & 17 & 1.8974359 & 0.34166667 \\
\hline KRT23 & 17 & 2 & 0.30769231 \\
\hline DACH1 & 16 & 1.94871795 & 0.175 \\
\hline FCN3 & 15 & 1.93589744 & 0.24761905 \\
\hline POSTN & 15 & 2.02564103 & 0.23076923 \\
\hline EFNA1 & 15 & 1.97435897 & 0.37179487 \\
\hline COL9A3 & 15 & 1.93589744 & 0.28571429 \\
\hline BGN & 15 & 1.93589744 & 0.266666667 \\
\hline MLXIPL & 15 & 1.94871795 & 0.48351648 \\
\hline
\end{tabular}



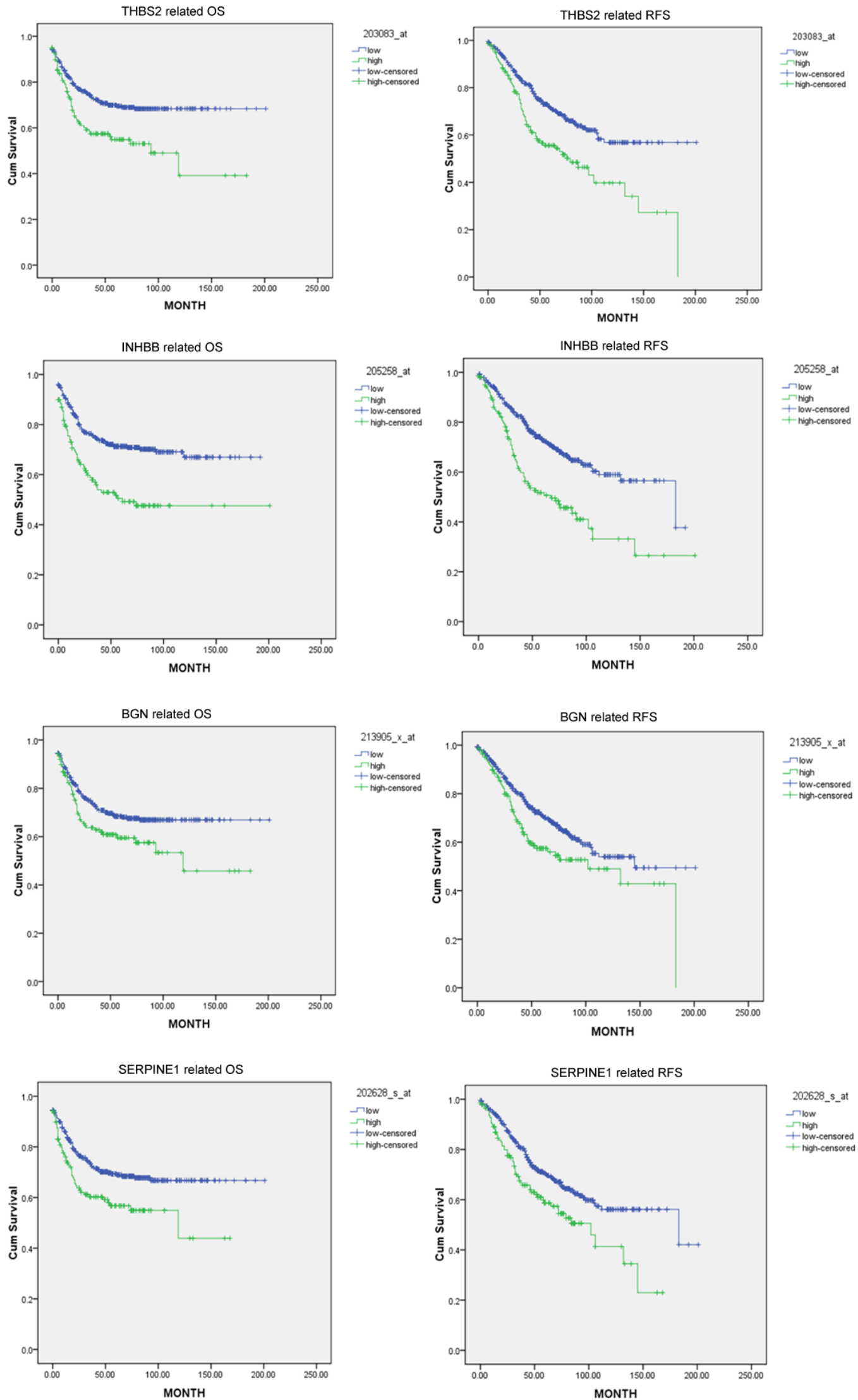

Figure 6: THBS2, INHBB, BGN, and SERPIN1 were correlated with poor OS and RFS. Cut-off value was selected as the upper quartiles of each gene ranked by expression values. 

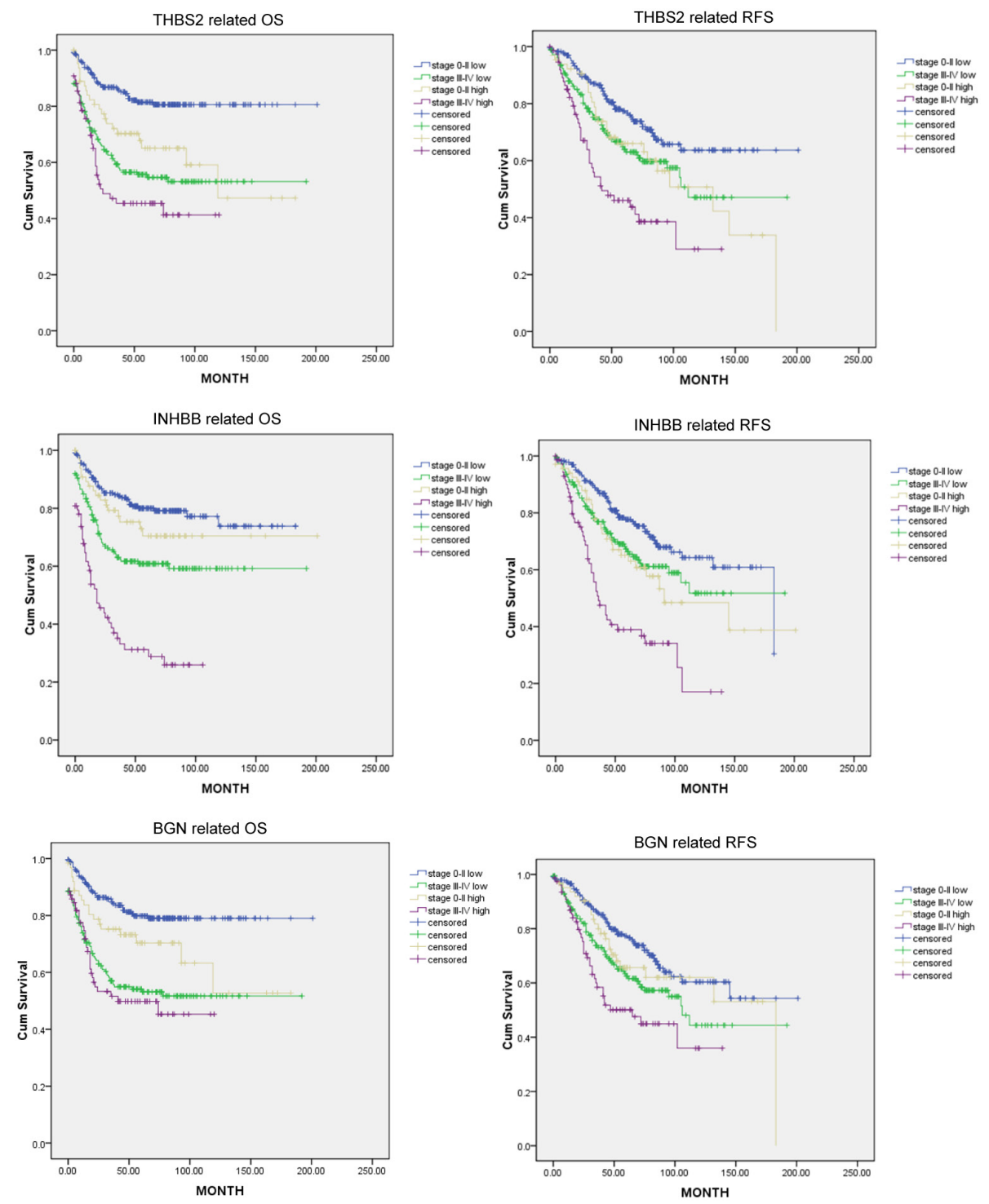

Figure 7: Kaplan-Meier plot analyses of THBS2, INHBB and BGN (cut-off value of high and low group: upper quartiles) in stage 0-II and stage III-IV.
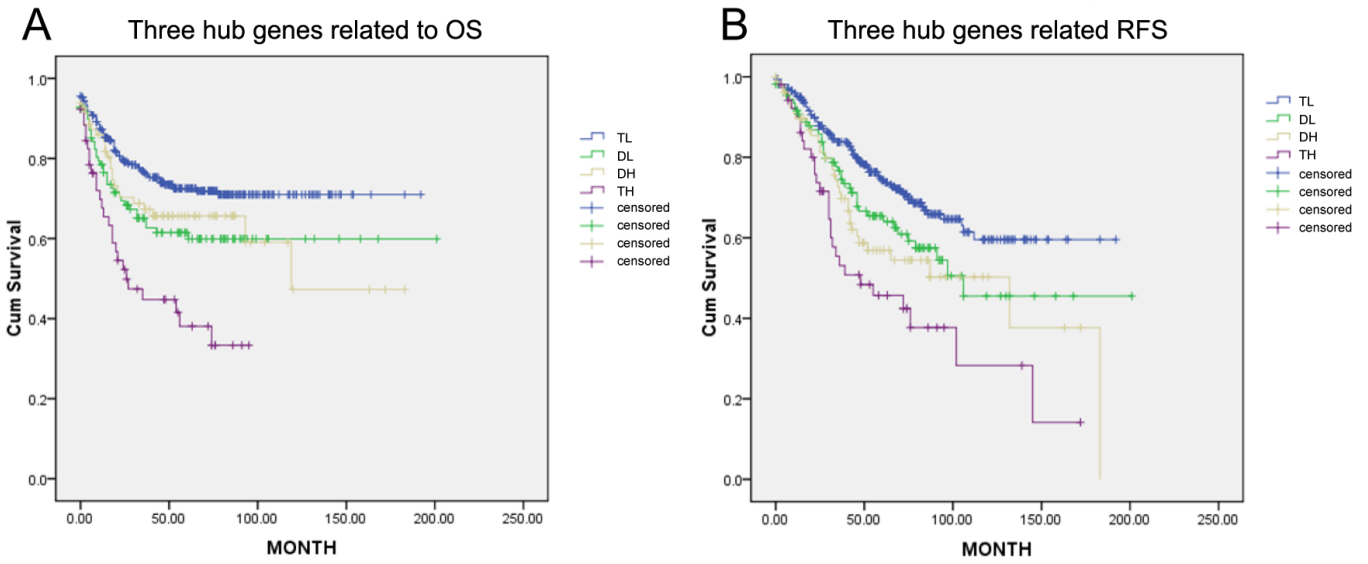

Figure 8: THBS2, INHBB and BGN were classified into four groups (TL, DL, DP and TH; cut-off value of high and low group: upper quartiles). OS and RFS were significantly different between these groups $(\mathrm{p}<0.05)$. TN has the best survival while TH the worst. 
the role of INHBB in gastrointestinal cancer, especially in CRC, has not been thoroughly studied from now on. Our analysis confirmed the overexpression of INHBB in CRCLM and its association with poorer OS and RFS, which may result from its function of inhibiting apoptosis.

BGN gene encodes a member of the small leucinerich proteglycan family of proteins. The encoded protein may contribute to atherosclerosis and aortic valve stenosis in human patients. It seems to enhance the ability of migration and invasion in endometrial cancer [33]. BGN also promotes tumor invasion and metastasis of gastric cancer both in vitro and in vivo [34]. Activated FAK signaling pathway, which regulates cell adhesion and motility by relaying ECM signals from integrin to the intracellular compartment, leads to tumor invasion and metastasis [35]. However, there are few reports on BGN in CRC. In the present study, BGN was found overexpression in CRCLM, and it was correlated with poorer OS and RFS. The underlying molecular mechanism was not clear at present, but FAK signaling pathway may take an important role in this process.

The correlation among three hub genes and survival were also explored in respective to TNM stage. THBS2 and INHBB were independent prognostic biomarker for OS and RFS in both stage 0-II and stage III-IV, while the prognostic value of BGN was associated with TNM staging. Nevertheless, synchronous high expression of these three hub genes indicates the worst clinical outcome, while synchronous low level indicates the best, emphasizing their contributions to poor prognosis.

In summary, several critical signaling pathways such as chemotaxis, coagulation and lipid metabolism may have critical roles in the processes of CRC carcinogenesis and liver metastasis. THBS2, INHBB and BGN are prognostic markers and potential therapeutic targets for CRC. Validation of large cohorts and wet lab experiments are still needed before achieving any clinical significance.

\section{MATERIALS AND METHODS}

\section{Ethics statement}

The databases used in our study are available online. Anyone is permitted to use all the data in the website of ArrayExpress (http://www.ebi.ac.uk/arrayexpress/), which contains more than 65 thousands of experiments and about 2 millions of assays. It also supports for a search facility to get what type of array and the related information we want. Gene expression datasets were downloaded from Gene Expression Omnibus (GEO) website (www.ncbi. nlm.nih.gov/geo/), which can be linked in the experiments searched out in ArrayExpress. GEO is a public functional genomics data and open for everyone. It contains more than 4300 datasets, 77000 series and 2000000 samples. It provides us some useful tools, such as GEO2R, to get the information we needs. Since all the data are publicly available, The Research Ethics Committee of Zhejiang
Provincial People's Hospital therefore waived the requirement for ethical approval.

\section{Selection of databases}

We searched in the ArrayExpress with the condition of colorectal adenocarcinoma and liver metastasis, filtered by organism of Homo sapiens, experiment type of array assay and RNA assay. As a result, we searched out 29 experiments that satisfied the conditions. According to the total sample capacity and the volume of colorectal mucosa, primary tumor and liver metastasis respectively, we chose GSE68468 as the database looking for upregulated genes both in primary CRC and in liver metastasis. Then we researched the ArrayExpress with the condition of colorectal adenocarcinoma, filtered by organism of Homo sapiens, experiment type of array assay and RNA assay. As a result, there are 479 experiments satisfied. According to the dataintegrity and sample quantity, we focused on the dataset of GSE40967 on the platform of GPL570, which contains the follow-up of OS and RFS in 562 samples testing the gene expression of primary tumor.

\section{Genomic analyses}

GEO dataset [36] GSE68468 [37], which containing 54 normal colon mucosa, 186 primary tumors and 47 liver metastases, was reanalyzed for discovering gene associated with both colon carcinogenesis and liver metastasis. While GSE40967 [38] was used for validating the prognostic value of these genes in 562 patients with colon cancer. Differentially expressed genes were computed using Limma package in $\mathrm{R}$ environment (version 3.2.1, R Foundation for Statistical Computing [http://www.r-project.org/]). Venn diagram was plotted by Venny online software (Oliveros, J.C. [http://bioinfogp. cnb.csic.es/tools/venny/index.html]). $\mathrm{MeV}$ was employed for Heat map and clustering analyses [39]. Function enrichment was performed using GATHER [40], while gene-gene interaction network was constructed by utilizing GeneMANIA plugin [41].

\section{Statistical analyses}

Differentially expressed genes were selected by the following criteria: $\mathrm{P}<0.05$, Log 2 Transformed Fold Change $>0.6$ or $<-0.6$. Kaplan-meier plot analysis was performed using SPSS software (IBM, version 21.0) and log-rank test was employed to evaluate statistical significance. All the data were analyzed using standard statistical tests. Significance was defined as $\mathrm{P}$ value less than 0.05 .

\section{ACKNOWLEDGMENTS}

We thank Key Laboratory of Gastroenterology of Zhejiang Province for helpful suggestion and guidance. This study was supported by Medical science Foundation 
of National Health and Family planning commission (No. WKJ-ZJ-1716). Natural Science Foundation of Zhejiang Province (No. LY17H160065). Research Foundation of Zhejiang Provincial Administration of Traditional Chinese Medicine (No. 2016ZB018).

\section{CONFLICTS OF INTEREST}

The authors declared that no competing interests exist.

\section{REFERENCES}

1. Nishihara R, Wu K, Lochhead P, Morikawa T, Liao X, Qian ZR, Inamura K, Kim SA, Kuchiba A, Yamauchi M, Imamura Y, Willett WC, Rosner BA, et al. Long-term colorectal-cancer incidence and mortality after lower endoscopy. The New England journal of medicine. 2013; 369:1095-1105.

2. Ferlay J, Steliarova-Foucher E, Lortet-Tieulent J, Rosso S, Coebergh JW, Comber H, Forman D, Bray F. Cancer incidence and mortality patterns in Europe: estimates for 40 countries in 2012. European journal of cancer (Oxford, England: 1990). 2013; 49:1374-1403.

3. Ferlay J, Shin HR, Bray F, Forman D, Mathers C, Parkin DM. Estimates of worldwide burden of cancer in 2008: GLOBOCAN 2008. International journal of cancer. 2010; 127:2893-2917.

4. Cunningham D, Atkin W, Lenz HJ, Lynch HT, Minsky B, Nordlinger B, Starling N. Colorectal cancer. Lancet (London, England). 2010; 375:1030-1047.

5. Kanas GP, Taylor A, Primrose JN, Langeberg WJ, Kelsh MA, Mowat FS, Alexander DD, Choti MA, Poston G. Survival after liver resection in metastatic colorectal cancer: review and meta-analysis of prognostic factors. Clinical epidemiology. 2012; 4:283-301.

6. Spolverato G, Ejaz A, Azad N, Pawlik TM. Surgery for colorectal liver metastases: The evolution of determining prognosis. World journal of gastrointestinal oncology. 2013; 5:207-221.

7. Kopetz S, Hoff PM, Morris JS, Wolff RA, Eng C, Glover KY, Adinin R, Overman MJ, Valero V, Wen S, Lieu C, Yan $\mathrm{S}$, Tran HT, et al. Phase II trial of infusional fluorouracil, irinotecan, and bevacizumab for metastatic colorectal cancer: efficacy and circulating angiogenic biomarkers associated with therapeutic resistance. Journal of clinical oncology. 2010; 28:453-459.

8. Meyerhardt JA, Li L, Sanoff HK, Carpenter Wt, Schrag D. Effectiveness of bevacizumab with first-line combination chemotherapy for Medicare patients with stage IV colorectal cancer. Journal of clinical oncology. 2012; 30:608-615.

9. Rojas Llimpe FL, Di Fabio F, Ercolani G, Giampalma E, Cappelli A, Serra C, Castellucci P, D'Errico A, Golfieri
R, Pinna AD, Pinto C. Imaging in resectable colorectal liver metastasis patients with or without preoperative chemotherapy: results of the PROMETEO-01 study. British journal of cancer. 2014; 111:667-673.

10. Pavon MA, Arroyo-Solera I, Tellez-Gabriel M, Leon X, Viros D, Lopez M, Gallardo A, Cespedes MV, Casanova I, Lopez-Pousa A, Mangues MA, Quer M, Barnadas A, et al. Enhanced cell migration and apoptosis resistance may underlie the association between high SERPINE1 expression and poor outcome in head and neck carcinoma patients. Oncotarget. 2015; 6:29016-29033. doi: 10.18632/ oncotarget.5032.

11. Mazzoccoli G, Pazienza V, Panza A, Valvano MR, Benegiamo G, Vinciguerra M, Andriulli A, Piepoli A. ARNTL2 and SERPINE1: potential biomarkers for tumor aggressiveness in colorectal cancer. Journal of cancer research and clinical oncology. 2012; 138:501-511.

12. Adam R, de Gramont A, Figueras J, Kokudo N, Kunstlinger F, Loyer E, Poston G, Rougier P, Rubbia-Brandt L, Sobrero A, Teh C, Tejpar S, Van Cutsem E, et al. Managing synchronous liver metastases from colorectal cancer: a multidisciplinary international consensus. Cancer treatment reviews. 2015; 41:729-741.

13. Jung SW, Kim DS, Yu YD, Han JH, Suh SO. Risk factors for cancer recurrence or death within 6 months after liver resection in patients with colorectal cancer liver metastasis. Annals of surgical treatment and research. 2016; 90:257-264.

14. Cheng D, Zhao S, Tang H, Zhang D, Sun H, Yu F, Jiang W, Yue B, Wang J, Zhang M, Yu Y, Liu X, Sun X, et al. MicroRNA-20a-5p promotes colorectal cancer invasion and metastasis by downregulating Smad4. Oncotarget. 2016; 7:45199-45213. doi: 10.18632/oncotarget.9900.

15. Cohen SA, Turner EH, Beightol MB, Jacobson A, Gooley TA, Salipante SJ, Haraldsdottir S, Smith C, Scroggins S, Tait JF, Grady WM, Lin EH, Cohn DE, et al. Frequent PIK3CA Mutations in Colorectal and Endometrial Tumors With 2 or More Somatic Mutations in Mismatch Repair Genes. Gastroenterology. 2016; 151:440-447.e441.

16. Park JH, Powell AG, Roxburgh CS, Horgan PG, McMillan DC, Edwards J. Mismatch repair status in patients with primary operable colorectal cancer: associations with the local and systemic tumour environment. British journal of cancer. 2016; 114:562-570.

17. Savio AJ, Daftary D, Dicks E, Buchanan DD, Parfrey PS, Young JP, Weisenberger D, Green RC, Gallinger S, McLaughlin JR, Knight JA, Bapat B. Promoter methylation of ITF2, but not APC, is associated with microsatellite instability in two populations of colorectal cancer patients. BMC cancer. 2016; 16:113.

18. Nguyen DX, Bos PD, Massague J. Metastasis: from dissemination to organ-specific colonization. Nature reviews Cancer. 2009; 9:274-284. 
19. Gay LJ, Felding-Habermann B. Contribution of platelets to tumour metastasis. Nature reviews Cancer. 2011; 11:123-134.

20. Karpatkin S, Pearlstein E. Role of platelets in tumor cell metastases. Annals of internal medicine. 1981; 95:636-641.

21. Nieswandt B, Hafner M, Echtenacher B, Mannel DN. Lysis of tumor cells by natural killer cells in mice is impeded by platelets. Cancer research. 1999; 59:1295-1300.

22. Im JH, Fu W, Wang H, Bhatia SK, Hammer DA, Kowalska MA, Muschel RJ. Coagulation facilitates tumor cell spreading in the pulmonary vasculature during early metastatic colony formation. Cancer research. 2004; 64:8613-8619.

23. Jain S, Zuka M, Liu J, Russell S, Dent J, Guerrero JA, Forsyth J, Maruszak B, Gartner TK, Felding-Habermann B, Ware J. Platelet glycoprotein Ib alpha supports experimental lung metastasis. Proceedings of the National Academy of Sciences of the United States of America. 2007; 104:9024-9028.

24. Sang Y, Chen MY, Luo D, Zhang RH, Wang L, Li M, Luo R, Qian CN, Shao JY, Zeng YX, Kang T. TEL2 suppresses metastasis by down-regulating SERPINE1 in nasopharyngeal carcinoma. Oncotarget. 2015; 6:2924029253. doi: 10.18632/oncotarget.5074.

25. Hanatani S, Izumiya Y, Takashio S, Kimura Y, Araki S, Rokutanda T, Tsujita K, Yamamoto E, Tanaka T, Yamamuro M, Kojima S, Tayama S, Kaikita K, et al. Circulating thrombospondin-2 reflects disease severity and predicts outcome of heart failure with reduced ejection fraction. Circulation journal. 2014; 78:903-910.

26. Hsu CW, Yu JS, Peng PH, Liu SC, Chang YS, Chang KP, $\mathrm{Wu}$ CC. Secretome profiling of primary cells reveals that THBS2 is a salivary biomarker of oral cavity squamous cell carcinoma. Journal of proteome research. 2014; 13:4796-4807.

27. Yang S, Shin J, Park KH, Jeung HC, Rha SY, Noh SH, Yang WI, Chung HC. Molecular basis of the differences between normal and tumor tissues of gastric cancer. Biochimica et biophysica acta. 2007; 1772:1033-1040.

28. Sun R, Wu J, Chen Y, Lu M, Zhang S, Lu D, Li Y. Down regulation of Thrombospondin2 predicts poor prognosis in patients with gastric cancer. Molecular cancer. 2014; 13:225.

29. Slavin S, Yeh CR, Da J, Yu S, Miyamoto H, Messing EM, Guancial E, Yeh S. Estrogen receptor alpha in cancer-associated fibroblasts suppresses prostate cancer invasion via modulation of thrombospondin 2 and matrix metalloproteinase 3. Carcinogenesis. 2014; 35:1301-1309.

30. Koch M, Hussein F, Woeste A, Grundker C, Frontzek K, Emons G, Hawighorst T. CD36-mediated activation of endothelial cell apoptosis by an $\mathrm{N}$-terminal recombinant fragment of thrombospondin-2 inhibits breast cancer growth and metastasis in vivo. Breast cancer research and treatment. 2011; 128:337-346.

31. Mylonas I. Inhibin-alpha, -betaA and -betaB subunits in uterine non-endometrioid carcinomas: prognostic significance and clinical implications. European journal of cancer (Oxford, England: 1990). 2010; 46:2485-2493.

32. M'Baye M, Hua G, Khan HA, Yang L. RNAi-mediated knockdown of INHBB increases apoptosis and inhibits steroidogenesis in mouse granulosa cells. The Journal of reproduction and development. 2015; 61:391-397.

33. Sun H, Wang X, Zhang Y, Che X, Liu Z, Zhang L, Qiu C, Lv Q, Jiang J. Biglycan enhances the ability of migration and invasion in endometrial cancer. Archives of gynecology and obstetrics. 2016; 293:429-438.

34. Hu L, Duan YT, Li JF, Su LP, Yan M, Zhu ZG, Liu BY, Yang QM. Biglycan enhances gastric cancer invasion by activating FAK signaling pathway. Oncotarget. 2014; 5:1885-1896. doi: 10.18632/oncotarget.1871.

35. Zhao J, Guan JL. Signal transduction by focal adhesion kinase in cancer. Cancer metastasis reviews. 2009; 28:35-49.

36. Barrett T, Wilhite SE, Ledoux P, Evangelista C, Kim IF, Tomashevsky M, Marshall KA, Phillippy KH, Sherman PM, Holko M, Yefanov A, Lee H, Zhang N, et al. NCBI GEO: archive for functional genomics data sets - update. Nucleic acids research. 2013; 41:D991-995.

37. Sheffer M, Bacolod MD, Zuk O, Giardina SF, Pincas H, Barany F, Paty PB, Gerald WL, Notterman DA, Domany E. Association of survival and disease progression with chromosomal instability: a genomic exploration of colorectal cancer. Proceedings of the National Academy of Sciences of the United States of America. 2009; 106:7131-7136.

38. Marisa L, de Reynies A, Duval A, Selves J, Gaub MP, Vescovo L, Etienne-Grimaldi MC, Schiappa R, Guenot D, Ayadi M, Kirzin S, Chazal M, Flejou JF, et al. Gene expression classification of colon cancer into molecular subtypes: characterization, validation, and prognostic value. PLoS medicine. 2013; 10:e1001453.

39. Saeed AI, Sharov V, White J, Li J, Liang W, Bhagabati N, Braisted J, Klapa M, Currier T, Thiagarajan M, Sturn A, Snuffin M, Rezantsev A, et al. TM4: a free, open-source system for microarray data management and analysis. BioTechniques. 2003; 34:374-378.

40. Chang JT, Nevins JR. GATHER: a systems approach to interpreting genomic signatures. Bioinformatics (Oxford, England). 2006; 22:2926-2933.

41. Montojo J, Zuberi K, Rodriguez H, Kazi F, Wright G, Donaldson SL, Morris Q, Bader GD. GeneMANIA Cytoscape plugin: fast gene function predictions on the desktop. Bioinformatics (Oxford, England). 2010; 26:2927-2928. 